\title{
INSPIRASI OTORITAS \\ MANAJEMEN MODERN \\ UNTUK KEPALA SEKOLAH
}

\section{Rokhmat Kamal}

Universitas Nahdlatul Ulama Sidoarjo

\section{PENDAHULUAN}

Jika ada satu hal yang harus bersedia diberikan oleh siapa pun dalam posisi otoritas mana pun untuk menginspirasi tindakan dan pencapaian, itu adalah kepemimpinan. Termasuk juga untuk kepala sekolah dan wirausahawan pendidikan. Jadi bagaimana dengan sekolah kita dan para guru dan admin yang memandu kebijakan mereka? Apa yang bisa kita anggap sebagai praktik terbaik kepemimpinan sekolah yang paling penting untuk diikuti agar sekolah mana pun sukses?. Tentu saja akan membantu untuk pertama-tama mendefinisikan seperti apa sekolah yang "sukses" itu. Mungkin itu akan berarti hal yang berbeda bagi pendidik yang berbeda, tetapi inilah satu visi untuk Anda pertimbangkan. Bagi saya, sekolah yang sukses menempatkan prioritas pada pembelajaran yang berfokus pada masa depan, dan berupaya 
membimbing staf dan siswa agar memiliki hasrat untuk belajar, dan untuk tumbuh secara kreatif dan kolaboratif. Selain itu, sekolah yang sukses berupaya membuat model dan mendorong praktik terbaik kepemimpinan sekolah sebagai sesuatu yang tidak hanya menjadi tanggung jawab administrator. Dengan kata lain, sekolah yang sukses menyadari bahwa kepemimpinan sejati adalah urusan semua orang di bawah atapnya - pemilik, guru, admin, dan siswa samasama bekerja sama untuk membuat sekolah mereka luar biasa. Ada beberapa langkah yang harus diambil dan tips yang harus diperhatikan untuk membantu Anda melalui proses mengelola sekolah dan bisnis pendidikan Anda.

\section{NILAI DAN INTEGRITAS}

Nilai dan integritas pribadi Anda adalah yang terpenting. Ketahui apa itu sebelum Anda mulai di posisi itu (Driscoll, 2018). Cara memimpin sekolah adalah senantiasa musyawarah serta sharing bersama para guru atau dengan siapapun dan tetap mendekat pada Allah SWT (Yuniarti, Kautsari, Sholichah, Purnomo, \& Rosyidah, 2017). 


\section{KALENDER TAHUNAN KEPALA SEKOLAH SEKUNDER}

Kalender ini akan membantu Anda menyimpan ikhtisar bulan ke bulan tentang apa yang ada di depan sehingga Anda dapat membawa koherensi ke dalam perencanaan Anda (Educational Leaders, 2019). kesabaran dan komunikasi yang baik dengan masyarakat sekitar adalah kunci untuk dapat mengatasi masalah dan bisa bangkit dari keterpurukan manajemen pendidikan. Prinsip utama dan kepemimpinan wirausaha pendidikan adalah disiplin, kreatif, cerdas dan ulet (Qori'ah, Sholichah, Purnomo, \& Rosyidah, 2017).

\section{BANGUN KEPERCAYAAN}

Tips kelola sekolah adalah senantiasa belajar dan bekerja keras. Bersabarlah dengan masalah, sesungguhnya didalam kesulitan ada kemudahan (Sholichah, Istiqomah, Rosyidah, \& Purnomo, 2017). Bangun kepercayaan dan kepercayaan dalam komunitas sekolah Anda. Percaya diri dan mudah didekati. Luangkan waktu untuk mempelajari budaya, misi, dan visi sekolah. Jadilah terlihat, ajukan pertanyaan, hargai apa yang Anda lihat dan berikan pujian untuk praktik belajar mengajar yang efektif (Driscoll, 2018). 


\section{HIKAYAT PENDIDIKAN}

Hasil penelitian menunjukkan bahwa penerapan pembelajaran dapat meningkatkan prestasi siswa; dan tes menunjukkan bahwa prestasi belajar siswa kelas belajar lebih baik daripada siswa kelas konvensional (Iskandar, Rizal, Kurniasih, Sutiksno, \& Purnomo, 2018). Pendidikan itu sebuah perhiasan dalam kemakmuran dan tempat bernaung dalam kesengsaraan (Maula, Mufidah, Rosyidah, \& Purnomo, 2017). Guru merupakan seorang yag memilki tugas mulia sebagai pendidik dan pengajar sekaligus sebagai pembentuk kepribadian siswa (Maula et al., 2018). Cari ilmu yang bermanfaat dan patuhi aturan-aturan yang ada. Bijaksana dan pantang menyerah dalam belajar adalah kunci kesuksesan. Pendidikan adalah pelajaran yang harus kita pelajari setiap hari baik dari buku, lingkungan, teman, maupun keluarga agar kita tidak tertinggal (Qori'ah et al., 2017).

\section{GO DIGITAL}

Ada alasan mengapa kami mendaftarkan ini sebagai salah satu dari 5 keterampilan menghemat waktu terbaik mereka untuk kepala sekolah. Teknologi bukan hanya 'tren'. Ini dapat 
dimanfaatkan sebagai alat yang mengubah hidup yang dapat Anda gunakan untuk meningkatkan kinerja institusi Anda. Cari tahu alat baru apa yang digunakan pesaing Anda atau bahkan sekolah yang Anda cita-citakan dan adopsi yang paling menguntungkan Anda. Dorong staf Anda untuk juga menjadi ahli teknologi karena dua alasan yang sangat penting ini (Okoli, 2017).

\section{PENGEMBANGAN DIRI GURU}

Pemimpin sekolah dan wirausaha pendidikan seharusnya senantiasa menikmati proses karena tidak ada hal yang besar yang tidak dilakukan dari hal yang kecil. Semua butuh proses, karena kesuksesan tidak datang secara langsung tanpa berproses (Maula et al., 2017). Menawarkan kepada guru pengembangan profesional yang berarti Pastikan bahwa apa pun yang disajikan kepada mereka sepadan dengan waktu dan upaya mereka dan selaras dengan rencana peningkatan sekolah (Drewitt, 2017).

\section{TERORGANISASI}

Jika tidak ada organisasi yang tepat di kelas, siswa-siswa merasa bosan dan mulai berlaku tidak pantas. Akan lebih baik jika pelajaran direncsiswaan dengan benar, membuat 
persediaan siap dan dengan demikian diatur dalam segala hal. Selalu pikirkan barang yang bisa dipindahkan dan cari tahu sistem yang membantu melacak barang-barang itu (Edsys, 2016).

\section{DENGARKAN}

Banyak penelitian telah menunjukkan bahwa mendengarkan adalah salah satu kualitas terpenting dari seorang pemimpin yang hebat. Artikel "Saluran Bantuan Utama" mengatakan tentang mendengarkan: "Jika seorang guru menemui Anda dengan masalah, dengarkan dan tanyakan kepada guru apa yang menurut mereka harus dilakukan" (Watanabe-Crockett, 2018).

\section{AJARAN WIRAUSAHA}

Menjaga hubungan baik dengan wali siswa melalui melaksanakan janji dan pelayanan yang baik adalah bagian dari promosi wirausaha (Asitah, Usmawati, Rosyidah, \& Purnomo, 2017). Toleransi, bekerja sama, bertanggungjawab, dan amanah adalah prinsip wirausaha pendidikan (Nahdiyah, Amrina, Purnomo, \& Rosyidah, 2017). Edupreneur atau educational entrepreneur berasal dari dua kata yaitu education bermakna pendidikan dan entrepreneur bermakna 
pengusaha atau wirausahawan. Ada juga yang menyamakan istilah edupreneur dengan istilah teacherpreneur (Purnomo, 2017).

\section{BACA BUKU}

Pernahkah Anda bertemu dengan seorang pemimpin yang kuat yang bukan pembaca? (Bauer, 2019). Siswa perlu memahami apa yang diketahui dan apa yang diminta untuk memiliki kemampuan menjawab (Suci et al., 2018).

\section{TETAPKAN STRUKTUR PERTAMA}

Manajemen sekolah dilakukan dengan menerapkan standar kualitas dalam rekrutmen pengajar yaitu kedekatannya dengan amaliyah (Munjidah, Zannah, Purnomo, \& Rosyidah, 2017). Latih siswa untuk bekerja dan melakukan aktivitas mereka di lingkungan yang terstruktur. Begitu mereka memahami strukturnya, mereka seharusnya dapat bekerja di lingkungan yang tidak terstruktur tanpa kehilangan kendali (Edsys, 2016). 


\section{JANGAN LUPA UNTUK BERINVESTASI DALAM PENGEMBANGAN PROFESIONAL ANDA SENDIRI}

Guru merupakan seorang pendidik dan pengajar sekaligus sebagai pembentuk kepribadian siswa yang unggul, berwawasan dan baik (Maula et al., 2018). Luangkan waktu untuk merefleksikan kepemimpinan Anda, terus belajar dengan membaca, menghadiri pertemuan profesional, dan berbicara dengan para pemimpin lainnya (Drewitt, 2017).

\section{BERSERAH DIRI KEPADA TUHAN}

Pendidikan adalah kunci untuk membuka pintu emas kesuksesan. Tips mengelola institusi pendidikan adalah niat mendidik dan berjuang karena Allah ta'ala. Niscaya rintangan sebesar apapun akan terasa ringan dihadapan kita. Melihat anak mengenal Allah Ta'ala dan sukses akhlak dan pengetahuannya merupakan kebahagiaan pendidik (Yuniarti et al., 2017). Prinsip pendidikan adalah sosial (Asitah et al., 2017). Guru harus bisa membangun generasi muda untuk masa depan. Hiduplah untuk mengamalkan ilmu (Sholichah et al., 2017). Setiap manusia hamba Tuhan yang memiliki ilmu selayaknya harus mengamalkan ilmu tersebut 
(Asitah et al., 2017). Hubungan pendidikan antara guru dan murid itu seperti aliran listrik dengan lampu. Bagaimana lampu itu bisa menyala kalau aliran listriknya juga mati ?. Bagaimana murid itu bisa berprestasi sedangkan guru sendiri tidak pernah berprestasi dan mendoakan (Fidiana, Istiana, Rosyidah, \& Purnomo, 2017).

\section{DELEGASIKAN DENGAN TEPAT}

Menjadi kepala sekolah bisa sangat melelahkan. Ini sering diperkuat karena para pelaku secara alami biasanya mengendalikan orang-orang aneh. Mereka memiliki harapan yang tinggi tentang bagaimana hal-hal harus dilakukan sehingga sulit untuk membiarkan orang lain mengambil peran utama. Kepala sekolah yang berhasil dapat melewati ini karena mereka menyadari ada nilai dalam mendelegasikan. Pertama-tama, itu menggeser beban tanggung jawab dari Anda, membebaskan Anda untuk mengerjakan proyek lain. Selanjutnya, Anda dapat secara strategis membuat orang yang bertanggung jawab untuk proyek yang Anda tahu sesuai dengan kekuatan mereka dan akan membantu membangun kepercayaan diri mereka. Akhirnya, mendelegasikan mengurangi beban kerja keseluruhan Anda, yang pada gilirannya 
menjaga tingkat stres Anda minimum (Meador, 2019).

\section{KEMBANGKAN TIM YANG SANGAT EFEKTIF}

Pemimpin sekolah sebisanya tegas, toleran terhadap bawahannya dan mengayomi. Pendidikan adalah catatan masa lalu dan pengajaran masa kini untuk masa depan bangsa. Pendidikan adalah menyampaikan ilmu dan mentransformasi orang lain menjadi lebih baik (Fidiana et al., 2017). Mencari bakat yang tak terlihat di guru Anda dan memanfaatkannya. Berdayakan pemimpin formal dan informal. Percaya dan mendelegasikan tanggung jawab. Hargai tindakan guru Anda. Catatan penghargaan tulisan tangan atau kata pujian pribadi yang tenang selalu dihargai dan membantu membangun moral tim (Driscoll, 2018).

\section{PENUTUP}

Demikian tentang beberapa inspirasi tips untuk manajemen modern bagi kepada Sekolah. Irawan et al. (2018) menjelaskan bahwa pendidikan Indonesia membutuhkan peningkatan akses, mutu dan relevansi pendidikan untuk memberi manfaat membangun bagi pendidikan dan rakyat Indonesia. 


\section{REFERENCES}

Asitah, N., Usmawati, D. Z., Rosyidah, E., \&

Purnomo, A. (2017). MI Hasyim Asy'ari Ilmu Harus Terus Mengarus. In Wirausaha Pendidikan Indonesia (Jilid 2). Sidoarjo: UNUSIDA Press.

Bauer, D. (2019). 200 Tips for Effective School Leaders. Retrieved July 1, 2019, from https://www.betterleadersbetterschools.com/20 0-tips-effective-school-leaders/

Drewitt, P. (2017). 25 tips for School Principals.

Retrieved July 1, 2019, from https://www.linkedin.com/pulse/25-tips-schoolprincipals-paul-drewitt

Driscoll, M. (2018). 16 Success Tips for New 21st Century Principals. Retrieved July 1, 2019, from https://thinkstrategicforschools.com/16-successtips-new-21st-century-principals/

Edsys. (2016). 10 Awesome Tips to Manage School Discipline Issues. Retrieved June 29, 2019, from https://www.edsys.in/10-awesome-tips-tomanage-school-discipline-issues/

Educational Leaders. (2019). Guides for managing your school. Retrieved July 1, 2019, from http://www.educationalleaders.govt.nz/Managin g-your-school/Guides-for-managing-your-school Fidiana, W., Istiana, Z., Rosyidah, E., \& Purnomo, A. (2017). MINU Waru 2 Insan Berkilau Cahaya Manfaat. In Wirausaha Pendidikan Indonesia (Jilid 4). Sidoarjo: UNUSIDA Press. 
Irawan, D. E., Purnomo, A., Sutiksno, D. U., Abraham, J., Alamsyah, A., Saputra, D. H., ... Rosyidah, E. (2018). Kajian Pendidikan Tinggi IDRI untuk DPR RI dan Ristek Dikti 2018.

Bandung: ITB Press.

Iskandar, A., Rizal, M., Kurniasih, N., Sutiksno, D. U., \& Purnomo, A. (2018). The Effects of Multimedia Learning on Students Achievement in Terms of Cognitive Test Results. Journal of Physics: Conference Series, 1114(1), 012019. https://doi.org/10.1088/17426596/1114/1/012019

Maula, I., Asitah, N., Munjidah, A., Nahdiyah, K., Yuniarti, D., Sholichah, S. A., ... Qori'ah, S. (2018). Kontribusi Kreativitas Guru SD dalam Induksi Pembelajaran. https://doi.org/http://doi.org/10.17605/OSF.IO/ BS795

Maula, I., Mufidah, F. I., Rosyidah, E., \& Purnomo, A. (2017). SD Antawirya Islamic Javanese School Mother is Culture. In Wirausaha Pendidikan Indonesia (Jilid 1). Sidoarjo: UNUSIDA Press. Meador, D. (2019). 10 Things a Successful School Principal Does Differently. Retrieved July 1 , 2019, from https://www.thoughtco.com/thingsa-successful-school-principal-does-differently3194532

Munjidah, A., Zannah, I. P. N., Purnomo, A., \& Rosyidah, E. (2017). MI Thoriqussalam Berpegang Kepada Rosul. In Wirausaha Pendidikan Indonesia (Jilid 4). Sidoarjo: UNUSIDA Press. 
Nahdiyah, K., Amrina, S., Purnomo, A., \& Rosyidah, E. (2017). SD Taman Pendidikan Islam Porong Iman Kuat Bekal di Akhirat. In Wirausaha Pendidikan Indonesia (Jilid 2). Sidoarjo: UNUSIDA Press.

Okoli, A. (2017). 3 Little Changes that Would Make a Big Difference to your School Management. Retrieved July 1, 2019, from https://safsms.com/blog/3-changes-to-improveschool-management/

Purnomo, A. (2017). Pengertian Edupreneur. https://doi.org/10.31227/osf.io/8fnu6 Qori'ah, S., Sholichah, S. A., Purnomo, A., \& Rosyidah, E. (2017). Progresif Bumi Sholawat dengan Kebenaran Semua Pasti Ada Jalan. In Wirausaha Pendidikan Indonesia (Jilid 3). Sidoarjo: UNUSIDA Press.

Sholichah, S. A., Istiqomah, A., Rosyidah, E., \& Purnomo, A. (2017). MI Darun Najah Berfikir Berkarya Berdzikir. In Wirausaha Pendidikan Indonesia (Jilid 3). Sidoarjo: UNUSIDA Press. Suci, S. H. A., Rosyidah, E., Asitah, N., Aini, N., Murni, A. W., Anam, F., ... Kuraesin, A. D. (2018). Learning from Picture and Picture Action Research : Enhancement of Counting Ability on Division of Numbers for Primary School Students. Journal of Physics: Conference Series, 1114(1), 012044. https://doi.org/10.1088/1742$6596 / 1114 / 1 / 012044$

Watanabe-Crockett, L. (2018). The 10 School Leadership Best Practices That Make a Difference. Retrieved July 1, 2019, from https://www.wabisabilearning.com/blog/10school-leadership-best-practices 
Yuniarti, D., Kautsari, M. F., Sholichah, F., Purnomo, A., \& Rosyidah, E. (2017). SMP SMA Al-Amin Ponpes Bahrul Hidayah Serahkan pada Allah Ta'ala. In Wirausaha Pendidikan Indonesia (Jilid 1). Sidoarjo: UNUSIDA Press. 